\title{
Giant peritoneal loose body in the pelvic cavity confirmed by laparoscopic exploration: a case report and review of the literature
}

\author{
Hong Zhang ${ }^{*}$, Yun-zhi Ling, Ming-ming Cui, Zhi-xiu Xia, Yong Feng and Chun-sheng Chen
}

\begin{abstract}
A 51-year-old previously healthy male underwent a routine medical examination. Computed tomography and ultrasonography showed an oval-shaped mass that was about $50 \times 40 \mathrm{~mm}$ in size in the left iliac fossa. Prior to surgery, the lesion was suspected to be a teratoma with core calcification or stromal tumor derived from the rectosigmoid colon. During the procedure, a yellow-white, egg-shaped mass was discovered that was completely free from the pelvic cavity in front of the rectum. The giant, peritoneal loose body was taken out through the enlarged port site. Histological examination showed that the mass consisted of well-circumscribed, unencapsulated, paucicellular tissue, with an obviously hyalinized fibrosclerotic center. A giant peritoneal body is extremely rare. We report such a case and review previously published literature.
\end{abstract}

\section{Background}

Peritoneal loose bodies are rare. They are usually found at laparotomy or autopsy by accident. In most cases, these bodies are derived from appendix epiploica. The most common size of loose bodies is about from 5 to $20 \mathrm{~mm}$ in diameter. Occasionally, they grow to larger than $50 \mathrm{~mm}$ by absorbing protein from peritoneal serum $[1,2]$. We report a case of a giant peritoneal loose body measuring $50 \times 40 \times 40 \mathrm{~mm}$ in the pelvic cavity which happened in a 51 -year-old man and confirmed by laparoscopic exploration.

\section{Case presentation}

A previously healthy 51-year-old man underwent a routine medical examination. An incidental pelvic solid mass was detected on ultrasonography (Figure 1) and computed tomography (CT) (Figure 2). The oval-shaped mass was about $50 \times 40 \mathrm{~mm}$ in size and showed a lowdensity lesion with clear boundaries, a complete capsule, and two calcifications in the central part on the CT scan. The mass lay adjacent to the sigmoid colon in the left iliac fossa. The patient had no complaints or significant past medical history. No abnormality was found on

\footnotetext{
* Correspondence: haojiubujian1203@sina.cn

Department of Colorectal Surgery, Shengjing Hospital, China Medical

University, No. 36 SanHao Street, Heping District, Shenyang, Liaoning 110004, China
}

(c) 2015 Zhang et al.; licensee BioMed Central. This is an Open Access article distributed under the terms of the Creative

(c) 2015 Zhang et al.; licensee BioMed Central. This is an Open Access article distributed under the terms of the Creative
Commons Attribution License (http://creativecommons.org/licenses/by/4.0), which permits unrestricted use, distribution, and reproduction in any medium, provided the original work is properly credited. The Creative Commons Public Domain Dedication waiver (http://creativecommons.org/publicdomain/zero/1.0/) applies to the data made available in this article unless otherwise stated.

physical exam including digital rectal examination. Tumor markers and other laboratory tests were within the normal range.

Based on the present imaging findings, the preoperative diagnosis of teratoma with core calcification or stromal tumor derived from the rectosigmoid colon was suspected. Accordingly, diagnostic laparoscopic surgery was performed. A yellow-white, egg-shaped body that was completely free from the pelvic cavity was found in front of the rectum (Figure 3A). Further laparoscopic exploration of pelvic and abdominal organs demonstrated that the liver, stomach, intestine, colon, and rectum were all normal. Finally, the peritoneal loose body was put into an endoscopic retriever bag, taken out through the enlarged port site in the right lower abdomen, and sent for histopathological examination (Figure 3B).

On gross pathologic examination, the peritoneal loose body measured $50 \times 40 \times 40 \mathrm{~mm}$. It was yellow-white, oval in shape, and it had a bony-hard, smooth surface. The cross section displayed a thread-like appearance. There were two calcified cores filled with yellow cheeselike material, and the interval distance between the two cores was about $5 \mathrm{~mm}$ (Figure 4). Histologically, the lesion 


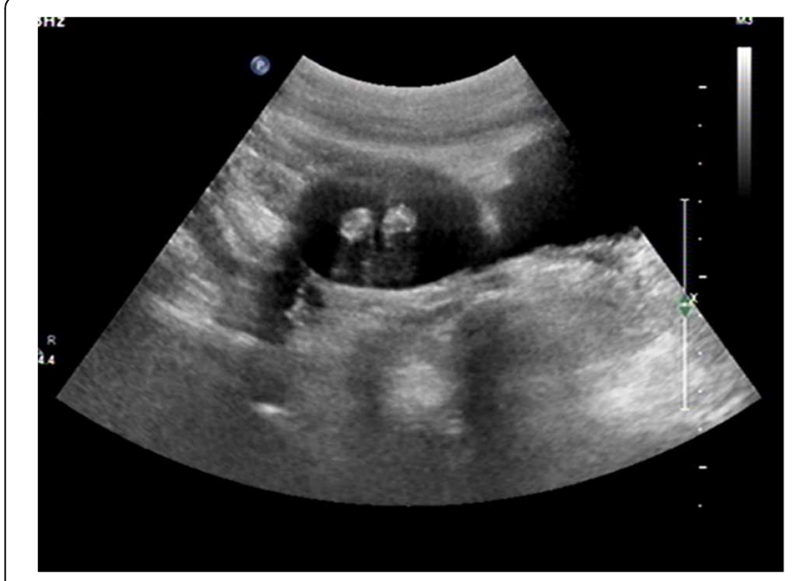

Figure 1 Two-dimensional ultrasound imaging showed a solid mass with clear boundary. It was hypoechoic with hyperechoic spots in the central part.

consisted of well-circumscribed, unencapsulated, paucicellular tissue, with an obviously hyalinized fibrosclerotic center. At the periphery, the lesion was paucicellular, containing spindled fibroblasts embedded in a collagenous stroma (Figure 5).

Our patient recovered well post-operatively. $\mathrm{He}$ was discharged from the hospital 2 days after surgery.

\section{Discussion}

Peritoneal loose bodies are also called peritoneal mice. There is limited information about the incidence of peritoneal loose bodies around the world. They are very rare and usually incidentally diagnosed during surgery or autopsy. The characteristics of 22 cases that have been reported are shown in Table 1; we found that peritoneal loose body is more common in males. The incidence rate ratio between males and females is 18:4. The age span of patients at the time of diagnosis ranges from 2 months to 79 years, and the majority occurs in patients between 50 and 70 years old. Most peritoneal loose bodies range from 5 to $25 \mathrm{~mm}$ in size and generally do not cause any symptoms. When the maximum diameter reaches more than $50 \mathrm{~mm}$, they can be called giant peritoneal loose bodies. The largest peritoneal loose body measured $95 \times 86 \mathrm{~mm}$ and was reported by Mohri et al. [1] in 2007. Giant peritoneal loose bodies are not usually associated with specific symptoms except for chronic abdominal pain in some cases [1-3]. In our case, the giant peritoneal loose body was $50 \times 40 \times$ $40 \mathrm{~mm}$ in size and did not cause any discomfort; it was found incidentally on physical examination. Occasionally, if the peritoneal loose bodies are large enough and in a particular location, patients may be admitted to the hospital with acute urinary retention $[4,5]$ or intestinal obstruction [6-8] due to extrinsic compression.

Thus far, the exact pathogenesis of peritoneal loose bodies has not been clearly defined. Possible sources include: (1) appendix epiploica, (2) omentum [9], (3) autoamputated adnexa [10], or (4) fat tissue in the pancreas [11]. The most common source is appendix epiploica. It is believed that the process is sequential. First, chronic torsion of the appendix epiploica occurs, and the blood supply is shut off, followed by saponification and calcification of fat tissue. Finally, the appendix epiploica detaches from the colon due to atrophy of the pedicle and becomes a peritoneal loose body. Many authors suggest that the body gradually absorbs protein from peritoneal serum. The size of the peritoneal loose body increases slowly, like a snowball. However, the growth speed of the peritoneal loose body and the factors that promote or inhibit growth are unknown. Mohri et al. [1] discovered a peritoneal loose body in a 73-

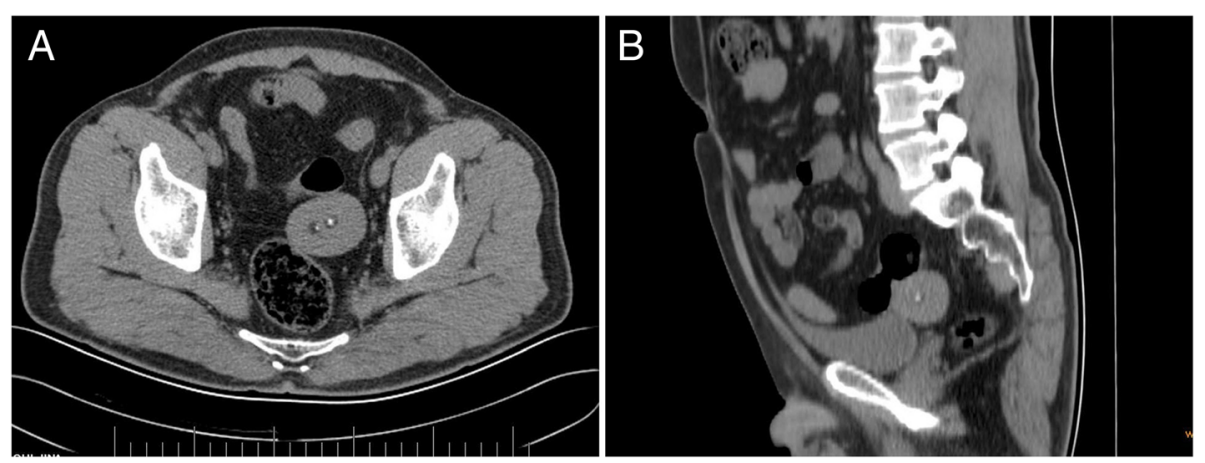

Figure 2 Abdominal computed tomography findings. (A) Axial image demonstrated a low-density lesion with complete capsule and two calcifications in the central part. (B) Sagittal image showed the mass adjacent to the sigmoid colon in the left iliac fossa. 

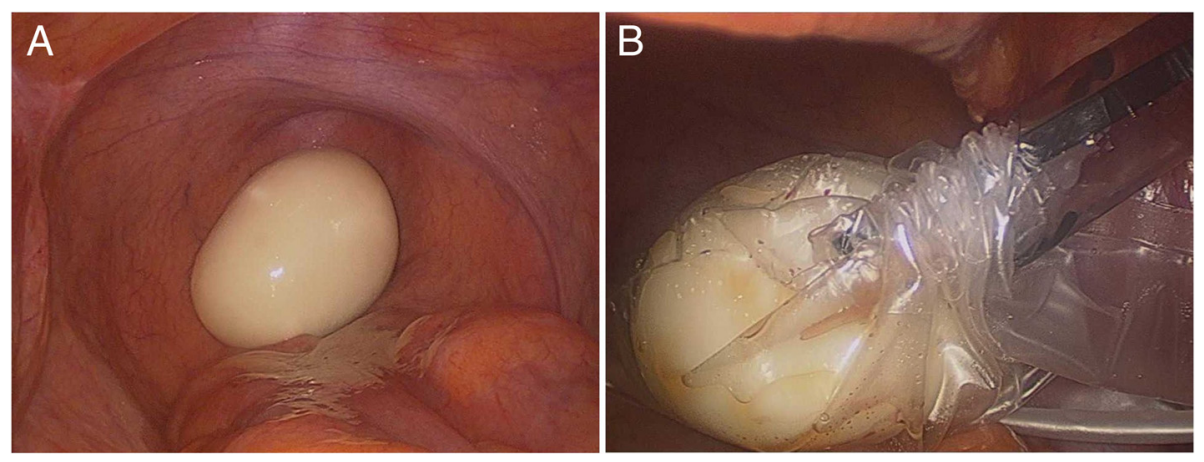

Figure 3 Laparoscopic findings. (A) A yellow-white, egg-shaped body that was completely free from the pelvic cavity was found in front of the rectum. (B) The body was put into an endoscopic retriever bag and taken out through the port site.

year-old man's pelvic cavity that grew from $73 \times$ $70 \mathrm{~mm}$ to $95 \times 75 \mathrm{~mm}$ in 5 years. In addition, there was another case [12] of a peritoneal loose body that did not significantly change in size or appearance in 3 years. Interestingly, Koga $\mathrm{K}$ et al. [10] removed a $30 \times 20 \mathrm{~mm}$ peritoneal loose body from a 33-year-old woman who, at 9 years of age, had adnexal torsion followed by calcification and autoamputation.

The differential diagnosis associated with peritoneal loose body include the following: (1) benign disease: leiomyoma, rhabdomyomas, teratoma, and fibroma; (2) malignant disease: colorectal cancer, ovarian cancer, and metastases; (3) calculous disease: urinary stones, gallstones, and appendix stones; (4) tubercular granuloma; and (5) others: calcification of lymph nodes, lymphoma, and foreign bodies. CT and MRI can be performed to distinguish peritoneal loose bodies from other lesions. For example, leiomyoma and some tumors enhance after injection of a contrast agent, while the appearance of peritoneal loose bodies remains unchanged.
Treatment is surgical removal because it is not easy to establish definite diagnosis preoperatively via physical examination and imaging technologies. Laparoscopic exploration is recommended [3,13-17]. Laparoscopy not only reduces surgical trauma but also shortens the patient's hospitalization time. In our case, the patient was discharged from the hospital 2 days after surgery. Moreover, the loose body can be removed through a slightly enlarged trocar incision, and patients will not have a scar.

Until now, there have been no reports about the leading cause of death or recurrence in patients with peritoneal loose body. No harm has been shown to patients who receive active treatment.

\section{Conclusions}

Peritoneal loose bodies are generally found incidentally. Clinically, if CT or other imaging shows an oval-shaped mass with or without calcifications in the central region, peritoneal loose body should be
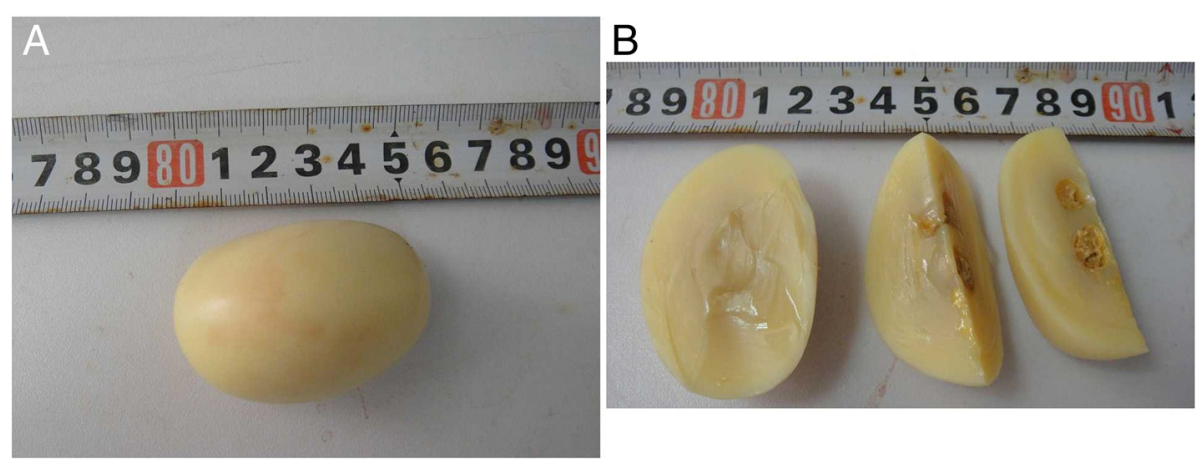

Figure 4 Gross pathologic examination. (A) The peritoneal loose body was $50 \times 40 \times 40 \mathrm{~mm}$ in size, oval-shaped, and yellow-white in appearance with a bony-hard, smooth surface, but without an obviously fibrous capsule. (B) The cross section displayed a thread-like appearance. There were two calcified cores filled with yellow cheese-like material. 

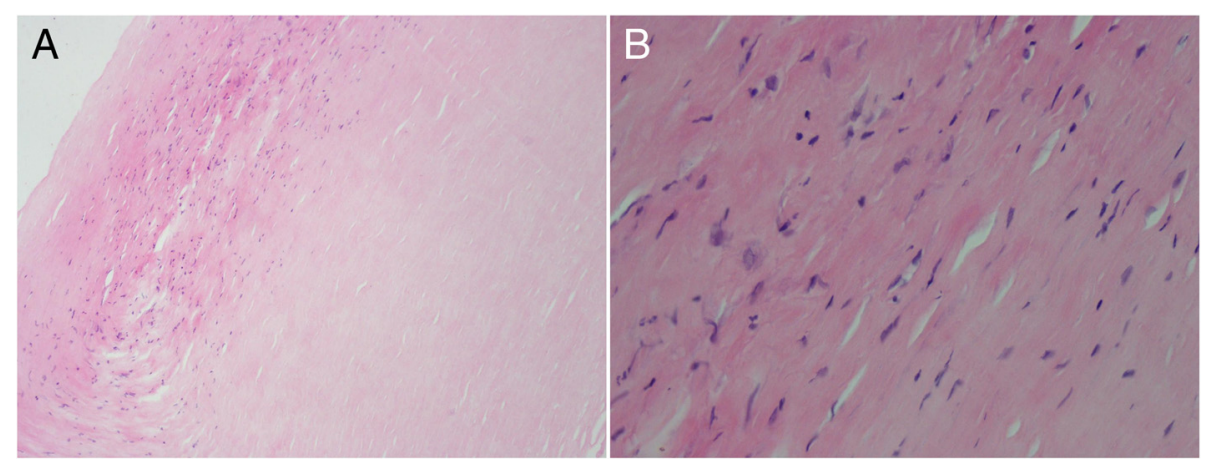

Figure 5 Histologic findings. (A) The lesion consisted of well-circumscribed, unencapsulated, paucicellular tissue, with an obviously hyalinized fibrosclerotic center $[\mathrm{HE}, \times 100]$. (B) At the periphery, the lesion was paucicellular, containing spindled fibroblasts embedded in a collagenous stroma. Scattered slit-like spaces were frequent $[\mathrm{HE}, \times 400]$.

considered. Surgical removal is recommended for the patient with acute retention of urine or intestinal obstruction. Additionally, laparoscopy may be the best choice when the preoperative diagnosis is not clear and the lesion does not cause any clinical symptoms.

\section{Consent}

Written informed consent was obtained from the patient for publication of this case report and any accompanying images. A copy of the written consent is available for review by the Editor-in-Chief of this journal.

Table 1 Summary of the information of 22 cases in the literature

\begin{tabular}{|c|c|c|c|c|c|c|c|}
\hline Author & Published year & Gender & Age & Symptoms & Size of PLB (mm) & $\begin{array}{l}\text { Weight of } \\
\text { PLB (g) }\end{array}$ & $\begin{array}{l}\text { Surgical } \\
\text { methods }\end{array}$ \\
\hline Mohri et al. [1] & 2007 & M & 73 years & Abdominal pain & $95 \times 75 \times 66$ & 220 & Open \\
\hline Hedawoo and Wagh [2] & 2010 & M & 65 years & Abdominal pain & $95 \times 86$ & - & Open \\
\hline Murat and Gettman [3] & 2004 & M & 47 years & Pelvic pain & $35 \times 28 \times 25$ & - & Laparoscopy \\
\hline Bhandarwar et al. [4] & 1996 & M & 65 years & Acute retention of urine & $90 \times 80$ & 210 & Open \\
\hline Shepherd [5] & 1951 & M & 79 years & Acute retention of urine & $70 \times 55$ & - & Open \\
\hline Sewkani et al. [6] & 2011 & M & 64 years & Abdominal pain & $70 \times 50$ & 74 & Open \\
\hline Ghosh et al. [7] & 2006 & M & 63 years & Intestinal obstruction & $58 \times 45 \times 37$ and $52 \times 45 \times 37$ & - & Open \\
\hline Kao et al. [8] & 2010 & $\mathrm{~F}$ & 69 years & Intestinal obstruction & $40 \times 30 \times 23$ & - & Open \\
\hline Kogao et al. [10] & 2010 & $\mathrm{~F}$ & 33 years & Infertility & $30 \times 20$ & - & Laparoscopy \\
\hline Gayer and Petrovitch [12] & 2011 & M & 59 years & Incidental & 30 & - & Untreated \\
\hline Nomura et al. [13] & 2003 & M & 63 years & Incidental & $50 \times 40 \times 30$ & - & Laparoscopy \\
\hline Asabe et al. [14] & 2005 & $\mathrm{~F}$ & 2 months & Urinary tract infection & 30 & - & Laparoscopy \\
\hline Kim et al. [15] & 2013 & M & 50 years & Incidental & $75 \times 70 \times 68$ & 160 & Laparoscopy \\
\hline Sahadev and Nagappa [16] & 2014 & M & 52 years & Abdominal pain & $70 \times 60$ & - & Laparoscopy \\
\hline Jang et al. [17] & 2012 & M & 60 years & Incidental & $45 \times 40 \times 30$ & - & Laparoscopy \\
\hline Nozu and Okumuta [18] & 2012 & M & 67 years & Incidental & 40 & - & Untreated \\
\hline Burns and James [19] & 1969 & $\mathrm{~F}$ & 33 years & Incidental & $18 \times 13$ & - & Open \\
\hline Maekawa [20] & 2013 & M & 58 years & Incidental & 20 & - & Open \\
\hline Makineni et al. [21] & 2014 & M & 52 years & Abdominal discomfort & 60 & - & Open \\
\hline Allam et al. [22] & 2013 & M & 77 years & Abdominal pain & 17 & - & Untreated \\
\hline Huang et al. [23] & 2011 & M & 55 years & Intestinal obstruction & - & - & Open \\
\hline Takada et al. [24] & 1998 & M & 79 years & Incidental & $70 \times 60$ and $70 \times 60$ & 78 and 66 & Open \\
\hline
\end{tabular}

PLB, peritoneal loose body. 


\section{Competing interests}

The authors declare that they have no competing interests.

\section{Authors' contributions}

$\mathrm{HZ}$ and $Y Z L$ were involved in drafting the manuscript. MMC and ZXX were involved in acquisition of data and preparing the figures. YF and CSC designed and revised the manuscript. All authors read and approved the final manuscript.

\section{Acknowledgements}

The study was financially supported by the Natural Science Foundation of Liaoning Province, China (2013021098).

Received: 23 December 2014 Accepted: 7 March 2015

Published online: 24 March 2015

\section{References}

1. Mohri T, Kato T, Suzuki H. A giant peritoneal loose body: report of a case. Am Surg. 2007;73(9):895-6.

2. Hedawoo JB, Wagh A. Giant peritoneal loose body in a patient with haemorrhoids. Trop Gastroenterol. 2010;31(2):132-3.

3. Murat FJ, Gettman MT. Free-floating organized fat necrosis: rare presentation of pelvic mass managed with laparoscopic techniques. Urology. 2004;63(1):176-7.

4. Bhandarwar AH, Desai W, Gajbhive RN, Deshraj BP. Acute retention of urine due to a loose peritoneal body. Br J Urol. 1996;78(6):951-2.

5. Shepherd JA. Peritoneal loose body causing acute retention of urine. $\mathrm{Br} J$ Surg. 1951;39(154):185-7.

6. Sewkani A, Jain A, Maudar K, Varshney S. 'Boiled egg' in the peritoneal cavity-a giant peritoneal loose body in a 64-year-old man: a case report. J Med Case Rep. 2011;5:297.

7. Ghosh P, Strong C, Naugler W, Haghighi P, Carthers JM. Peritoneal mice implicated in intestinal obstruction: report of a case and review of the literature. J Clin Gastroenterol. 2006;40(5):427-30.

8. Kao CH, Hsu KF, Fan HL, Li YF, Chen CJ. A case of intestinal obstruction caused by a peritoneal loose body mimicking gallstone ileus. Acta Gastroenterol Belg. 2010;73(3):413-4.

9. Ghabremani GG, White ME, Hoff FL, Gore RM, Miller JW, Christ ML. Appendices epiploicae of the colon: radiologic and pathologic feature. Radiographics. 1992;12:59-77.

10. Koga K, Hiroi H, Osuga Y, Nagai M, Yano T, Taketani Y. Autoamputated adnexa presents as a peritoneal loose body. Fertil Steril. 2010;93(3):967-8

11. Takabe K, Greenberg Jl, Blair SL. Giant peritoneal loose bodies. J Gastrointest Surg. 2006;10(3):465-8

12. Gayer G, Petrovitch I. CT diagnosis of a large peritoneal loose body: a case report and review of the literature. $\mathrm{Br} J$ Radiol. 2011;84(1000):83-5

13. Nomura H, Hata F, Yasoshima T, Kuwahara S, Naohara T, Nishimori H, et al. Giant peritoneal loose body in the pelvic cavity: report of a case. Surg Today. 2003;33:791-3.

14. Asabe K, Maekawa T, Yamashita Y, Shirakusa T. Endoscopic extraction of a peritoneal loose body: a case report of an infant. Pediatr Surg Int. 2005;21(5):388-9.

15. Kim HS, Sung JY, Park WS, Kim YW. A giant peritoneal loose body. Korean J Pathol. 2013;47(4):378-82.

16. Sahadev R, Nagappa PK. A case of peritoneal free floating calcified fibromyoma. J Clin Diagn Res. 2014;8(5):ND03-4.

17. Jang JT, Kang HJ, Yoon JY, Yoon SG. Giant peritoneal loose body in the pelvic cavity. J Korean Soc Coloproctol. 2012;28(2):108-10.

18. Nozu T, Okumura T. Peritoneal loose body. Intern Med. 2012;51(15):2057.

19. Burns JB, Rogers Jr JV. A sequestered ovary as a loose peritoneal body. J South Med J. 1969;62(8):995-9.

20. Maekawa T, Komine M, Murata S, Ohtsuki M. Peritoneal loose body: a case report and comparison with encapsulated fat necrosis. J Dermatol. 2013;40(12):1058-9.

21. Makineni $H$, Thejeswi P, Prabhu S, Bhat RR. Giant peritoneal loose body: a case report and review of literature. J Clin Diagn Res. 2014;8(1):187-8.
22. Allam T, Muzaffar R, Nguyen NC, Osman MM. Peritoneal mouse as detected on (18)F-FDG PET-CT. Front Oncol. 2013;3:83.

23. Huang $\mathrm{CH}$, Lin SC, Chang KC, Chow NH. Numerous peritoneal loose bodies with ileus. Histopathology. 2011;58(2):318-9.

24. Takada A, Moriya Y, Muramatsu Y, Sagae T. A case of giant peritoneal loose bodies mimicking calcified leiomyoma originating from the rectum. Jpn J Clin Oncol. 1998;28:441-2.

\section{Submit your next manuscript to BioMed Central and take full advantage of:}

- Convenient online submission

- Thorough peer review

- No space constraints or color figure charges

- Immediate publication on acceptance

- Inclusion in PubMed, CAS, Scopus and Google Scholar

- Research which is freely available for redistribution

Submit your manuscript at www.biomedcentral.com/submit 